\title{
Are there serious adverse effects of omega-3 polyunsaturated fatty acid supplements?
}

\author{
Klaus W. Lange ${ }^{\mathrm{a}^{*}}$, Yukiko Nakamura ${ }^{\mathrm{a}}$, Alexander M. Gosslau ${ }^{\mathrm{b}, \mathrm{c}}$ and Shiming Li ${ }^{\mathrm{c}}$ \\ aDepartment of Experimental Psychology, University of Regensburg, Germany \\ ${ }^{b}$ Department of Science (Biology), City University of New York, United States \\ 'Department of Food Science, Rutgers University, New Brunswick NJ, United States \\ *Corresponding author: Klaus W. Lange, Institute of Psychology, University of Regensburg, 93040 Regensburg, Germany. Tel: +49 941 \\ 9433815; Fax: +49 941 9434496; E-mail: klaus.lange@ur.de \\ DOI: $10.31665 / J F B .2019 .7192$ \\ Received: September 27, 2019; Revised received \& accepted: September 28, 2019 \\ Citation: Lange, K.W., Nakamura, Y., Gosslau, A.M., and Li, S. (2019). Are there serious adverse effects of omega-3 polyunsaturated fatty \\ acid supplements? J. Food Bioact. 7: 1-6.
}

\begin{abstract}
Dietary omega-3 polyunsaturated fatty acids (PUFAs) may reduce the risk of various diseases. Marine oils rich in omega-3 PUFAs have therefore become popular dietary supplements. Adverse effects need to be considered when administering omega-3 PUFAs. While unproblematic short-term adverse events linked to omega-3 PUFAs have been reported, long-term PUFA supplementation may be associated with increased cancer risk, possibly due to PUFAs, their oxidation products or added vitamin E. Large-scale trials have shown increased rates of prostate cancer in men taking $\alpha$-tocopherol supplementation. Omega-3 PUFAs are highly prone to oxidative degradation to lipid peroxides and secondary oxidation products, which may render them ineffective or harmful. Oil contained in omega-3 supplements may contain a mixture of omega-3 PUFAs, problematic additives, and unspecified levels of potentially toxic oxidation products. The health consequences of oxidized fish oil intake remain unclear. Given the harmful effects of oxidized lipid products demonstrated in animal experiments, caution is needed in the supplementation of PUFAs at high doses over extended periods of time and during vulnerable phases of life, such as prenatal development, childhood, and adolescence. A balanced approach should weigh the overall health benefits of omega-3 PUFAs against potentially harmful effects of their supplementation. Future research should address the development of effective antioxidants without side effects.
\end{abstract}

Keywords: Omega-3 fatty acids; Fish oil supplement; Oxidation; Vitamin E; Adverse effects; Cancer.

\section{Introduction}

Omega-3 polyunsaturated fatty acids (PUFAs) have attracted increasing attention in recent years due to claims of their beneficial role in the promotion of health and reduction in the risk of various diseases, such as cardiovascular diseases, type 2 diabetes, cancer, cognitive decline, neurodegenerative diseases, and mental disorders (Shahidi, 2015; Shahidi and Ambigaipalan, 2018; Lange, 2019a,b,c). Marine oils, rich in omega-3 PUFAs, have therefore become one of the most popular dietary supplements globally (Barnes et al., 2008). However, even when seemingly natural and healthy nutrients are administered, adverse effects should also be considered.

A consideration in regard to undesired side effects of omega-3 PUFAs is the form in which they are administered. Both dietary consumption and supplement intake could be problematic. Several potential risks need to be considered when omega-3 PUFAs are administered as part of the diet. An important natural source of these bioactives is fish and seafood; these may be contaminated with methylmercury, dioxins, and polychlorinated biphenyls, which may increase the risk for some cancers or may harm unborn children when consumed by the mother during pregnancy (Mozaf- 
farian and Rimm, 2006). The consumption of fish once or twice a week has been claimed to be unproblematic in this respect (Mozaffarian and Rimm, 2006). However, endocrine disruptors contained in fish and fish oil, such as bisphenols and small amounts of pesticides, may be associated with hormonal-based cancers, including prostate cancer (Gerber, 2012). Omega-3 fatty acid supplements may also contain contaminants. Commercially available fish-oil capsules should therefore be assessed for pollutants and certified by health agencies.

Intervention trials with omega-3 fatty acid supplements have reported no serious adverse reactions at the doses administered (Sydenham et al., 2012). The more common adverse effects of fish oil preparations, particularly in higher dosages, include nausea, fishy belching and loose stools (Mehta, 2004). These effects have caused the blinding of some of the earlier treatment studies of fish oils to be questioned (Damico et al., 2002). While, in general, omega-3 PUFAs do not seem to have clinically relevant effects on bleeding time (Eritsland et al., 1995), caution is needed when administering high doses, since these have been shown to prolong bleeding time (Emsley et al., 2002; Emsley et al., 2006). Since clinical researchers tend to distance themselves from adverse events (Ioannidis, 2009), underreporting of such events is common.

When similar rates of adverse events for omega-3 PUFAs compared with placebo are reported, this concerns unwanted effects in the short term only. A commonly neglected consideration is that adverse effects of omega-3 PUFAs may occur many years following supplementation and may therefore fail to be detected. Randomized controlled trials are the gold standard for measuring treatment effects. However, randomized clinical drug trials are often underpowered to detect late occurring and rare adverse effects. In contrast, non-randomized studies can include much larger samples and can follow patients for considerably longer periods in comparison with randomized trials, allowing for detection of rare and late adverse events. While non-randomized studies are of limited use in establishing the benefits of drugs, they appear more reliable in establishing harms.

A variety of observational and epidemiological studies can provide information regarding potential harms of PUFA supplementation. Available studies suggest that long-term administration of omega-3 PUFAs could cause adverse effects due to the PUFAs themselves, compounds produced by PUFA oxidation or antioxidants added to PUFA supplements, such as vitamin E.

\section{Omega-3 fatty acids}

On the basis of epidemiological, clinical, and experimental studies, it is commonly assumed that omega-3 PUFAs reduce the risk of various kinds of cancer (for review see Shahidi and Ambigaipalan, 2018). These purported effects are supported by several clinical studies. However, some systematic reviews have reported that the available evidence is insufficient to suggest a significant relationship between omega-3 PUFAs and cancer incidence (e.g. MacLean et al., 2006; Gerber, 2012). Factors that may have influenced the inconsistent results of omega-3 PUFAs in relation to cancer include differences in the amount, source, type, and form (ethyl esters or triacylglycerols) of omega-3 PUFAs, the ratio of omega-6 to omega-3 PUFAs, the proportions of EPA, DHA and docosapentaenoic acid in the preparations, and genetic factors (Berquin et al., 2007).

The findings of several studies suggest that the intake of omega-3 fatty acids can be associated with an elevated cancer risk.
For example, a prospective study from Norway investigating the relationship between diet, as assessed using a semi-quantitative food-frequency questionnaire, and the subsequent risk of cutaneous malignant melanoma in 50,757 individuals attending a health screening program (mean follow-up time of 6.9 years) found that cod liver oil supplementation and the intake of polyunsaturated fat were associated with a significantly increased risk of melanoma in women (Veierød et al., 1997).

Inflammation appears to play a role in carcinogenesis, including in the etiology of prostate cancer (Sfanos and De Marzo, 2012; Wang et al. 2009). Omega-3 PUFAs may have anticarcinogenic effects due, in part, to their anti-inflammatory activity (Larsson et al. 2004; Chapkin et al. 2009). However, a large prospective study examining the relationship between inflammation-associated phospholipid fatty acids and prostate cancer risk found no support for the claim that omega-3 fatty acids reduce the risk (Brasky et al., 2011). The findings of this study, in fact, suggest that docosahexaenoic acid (DHA) may increase high-grade prostate cancer risk (Brasky et al., 2011). Another large, prospective case-cohort study confirmed the finding of an elevated prostate cancer risk among men with high blood levels of omega-3 PUFAs. Statistically significant increases in risk were found for high-grade (by $71 \%$ ) and low-grade (by 44\%) disease and for eicosapentaenoic acid (EPA), docosapentaenoic acid (DPA) and DHA (Brasky et al., 2013). In a case-control study, an increase in prostate cancer risk was observed in the highest compared to the lowest quintile of plasma phospholipid EPA and DPA, by $14 \%$ and $16 \%$, respectively (Crowe et al., 2014). Although the above correlations do not provide conclusive evidence that the consumption of fish oil supplements or fish causes prostate cancer, the consistency of the results suggests that omega-3 fatty acids may be a factor in prostate tumorigenesis. The associations between prostate cancer and exposure to omega-3 fatty acids, as assessed by their blood levels, cannot distinguish between fish consumption and omega-3 supplementation. In addition, omega-3 PUFA supplements contain other compounds, such as oxidation products and vitamin E, which may be related to carcinogenesis.

\section{Oxidation products of omega-3 fatty acids}

As early as the 1950 s, concerns were raised regarding the safety of oxidized fish oil (Kaneda and Ishii, 1953; Matsuo, 1954). The toxic effects of some fish and marine animal oils in rats (Sahashi, 1933; Somekawa, 1933) were shown not to be caused by fish oil per se but rather by its oxidized form (Kaneda and Ishii, 1953; Matsuo, 1954).

Omega-3 PUFAs are highly prone to oxidation due to the large number of double bonds in their chemical structures (Arab-Tehrany et al., 2012; Benzie, 1996; Shahidi and Zhong, 2010). Oxidized fish oils could have altered biological activity rendering them ineffective or even harmful. The oxidation of PUFAs leads to the formation of free radicals as demonstrated both in vitro and in vivo (Spiteller, 2005). Omega-3 PUFAs are oxidized to primary lipid hydroperoxides and secondary oxidation products, i.e. aldehydes and ketones (Albert et al., 2013; Arab-Tehrany et al., 2012; Shahidi and Zhong, 2010). In cascade-like chain reactions, lipid peroxides hasten oxidation of other fatty acids, producing further lipid peroxides. The radicals and lipid peroxides formed following omega-3 PUFA oxidation are relatively stable compared to other reactive oxygen species (Gutowski and Kowalczyk, 2013). It has been speculated that omega-3 peroxides may lead to lipid membrane peroxidation, cell damage, and oxidative stress (Albert 
et al., 2013). Evidence of harmful effects of oxidized lipids has been provided by animal studies (Esterbauer, 1993). The findings of such studies suggest that lipid peroxidation may contribute to the pathophysiological changes in inflammation-associated diseases, including neurodegenerative diseases (Grimm et al., 2016; Maruyama et al., 2014; Pamplona et al., 2005; Yakubenko and Byzova, 2017). Chronic lipid peroxidation may be involved in the pathogenesis of Alzheimer's disease (Sayre et al., 1997) and in carcinogenesis (Bartsch and Nair, 2006). The intake of marine oil leads to increased plasma (Haglund et al., 1991) and urinary (Piche et al., 1988) malondialdehyde levels in mice and humans, due to absorption of peroxidized oil and in vivo oxidation (Piche et al., 1988), which can only partially be reduced by added antioxidants (Cho and Choi, 1994; Gonzalez et al., 1992; Piche et al., 1988). Malondialdehyde has been shown to induce DNA mutations (Basu and Marnett, 1983) and to cause thyroid tumors and skin cancer in animals (Marnett, 1999). Malondialdehyde exposure may also be related to an increased risk of breast cancer in women (Wang et al., 1996). In conclusion, it is essential to use formulations that are able to effectively preserve omega-3 PUFA bioactivity.

In animal studies, DHA molecules can be protected from oxidation by using microencapsulated omega-3 PUFA formulations (Hogan et al., 2003; Kolanowski et al., 2004). Dietary omega-3 supplements in humans should also be prevented from oxidizing. Even oils stored in the dark at $4{ }^{\circ} \mathrm{C}$ could oxidize to unacceptable levels within a few weeks of storage (Pak, 2005). Commercially available omega-3 PUFA supplements have been shown to be frequently oxidized (Fantoni et al., 1996, Fierens and Corthout, 2007; Halvorsen and Blomhoff, 2011; Kolanowski, 2004; Opperman and Benade, 2013). For example, the majority of fish oil supplements on sale in New Zealand were shown to contain PUFAs below the concentrations claimed by labels and also to be oxidized, with peroxide (primary oxidation product), anisidine (reflecting secondary oxidation products), and total oxidation values exceeding the recommended thresholds (Albert et al., 2015). Another study from New Zealand found that $14-28 \%$ of fish oil products did not comply with voluntary industry-set maximum limits on peroxide, anisidine, and total oxidation values (Bannenberg et al., 2017). In North America, 50\% of over-the-counter omega-3 PUFA supplements have been found to fall below at least one of the voluntary safety standards recommended for primary and secondary oxidation as well as total oxidation (Jackowski et al., 2015).

The antioxidant most commonly added to omega-3 supplements is $\alpha$-tocopherol. Phenolic compounds appear to be efficient in delaying omega-3 PUFA oxidation (Hasiewicz-Derkacz et al., 2015). Natural antioxidants such as myricetin, rosmarinic and carnosic acids have recently been demonstrated to be more effective in preventing oxidation of omega-3 PUFA oils than $\alpha$-tocopherol and synthetic antioxidants (Guitard et al., 2016). It should be emphasized, however, that the addition of antioxidants to fish oils decreases but does not prevent oxidation (Zuta et al., 2007). New antioxidants should be investigated in future studies. For example, esters of DHA with the main tea polyphenol epigallocatechin gallate have been shown to help stabilize DHA and also provided an antioxidant preparation (Zhong and Shahidi, 2011).

A randomized placebo-controlled study has investigated in humans the effects of oxidized versus non-oxidized oil administered for 7 weeks (Ottestad et al. 2012). No difference was observed between groups in respect to markers of in vivo lipid peroxidation, markers of antioxidant activity, C-reactive protein, or liver function tests (Ottestad et al. 2012). These findings suggest that oxidized marine omega-3 PUFAs may be unrelated to acute oxidative toxicity. However, the duration of this trial study was short, and long-term follow-up may be required to identify the health effects of chronic, low grade exposure to peroxides, aldehydes, or malondialdehyde. Furthermore, the study did not examine other important pathological markers, such as low density lipoprotein, specific inflammatory markers or markers of DNA damage.

Oxidation of trial oils may be responsible, at least partly, for the inconsistent effects of fish oil on health, including the primary and secondary prevention of cardiovascular disease (Bosch et al., 2012; Rizos et al., 2012; Wang et al., 2006; Yokoyama et al., 2007). Omega-3 supplementation trials have not reported the oxidative status of the oils investigated. The influence of oxidation on the efficacy or potential harmful effects of the supplements therefore remains unknown. However, studies in animals have demonstrated that oxidized lipid products can cause harm. The 2010 conclusion of the European Food Standards Authority Panel on Biological Hazards in regard to fish oil consumed by humans that, "information on the level of oxidation of fish oil ....... and related toxicological effects in humans is lacking" (EFSA Panel on Biological Hazards, 2010), remains salient today.

\section{Vitamin $\mathrm{E}$}

Many epidemiological studies have suggested preventive activity of vitamin E against cancer (Ju et al., 2010). However, several large-scale trials assessing the effects of $\alpha$-tocopherol, the most commonly used form of vitamin $\mathrm{E}$, failed to find a cancer preventive effect (Gaziano et al., 2009; Lee et al., 2005; Lippman et al., 2009).

Based on findings suggesting that vitamin $\mathrm{E}$ intake is associated with a reduced prostate cancer risk (Chan et al., 1999; Kirsh et al., 2006), the phase III, randomized, placebo-controlled Selenium and Vitamin E Cancer Prevention Trial (SELECT) of prostate cancer prevention was conducted, with incident prostate cancer as the primary endpoint (Lippman et al., 2009). The trial was terminated after 7 years of follow-up, since no beneficial effects of selenium, vitamin $\mathrm{E}$, or a combination of both were found, and a statistically significant benefit was impossible to ascertain with additional follow-up (Lippman et al., 2009). Furthermore, extended followup analysis found an elevated risk, by $17 \%$, of incident prostate cancer in the vitamin E alone group (Klein et al., 2011).

Several questions have been raised in regard to the association of vitamin $\mathrm{E}$ and cancer. For example, it has been proposed that, at the nutritional level, all forms of vitamin $\mathrm{E}$ are cancer preventive (Yang et al., 2012), since many observations have suggested that the dietary consumption or plasma levels of $\alpha$-tocopherol and other tocopherols correlates inversely with cancer risk (Helzlsouer et al., 2000; Huang et al., 2003; Mahabir et al., 2008; Ju et al., 2010). However, at the supranutritional level, $\alpha$-tocopherol administered as a supplement does not appear to be cancer preventive, as demonstrated in several cancer prevention trials (Gaziano et al., 2009; Klein et al., 2011; Lee et al., 2005; Lippman et al., 2009). This view is supported by observations in animal models, which have shown the cancer preventive activity of $\gamma$ - and $\delta$-tocopherols as well as of a naturally occurring mixture of tocopherols, while cancer preventive activity of $\alpha$-tocopherol was not apparent (for review see Yang et al., 2012). This suggests that vitamin E, administered in the diet or via supplements rich in $\gamma$ - and $\delta$-tocopherols, is cancer preventive, while high doses of $\alpha$-tocopherol supplements are not. Both mechanistic and preclinical animal studies have demonstrated that, in comparison with $\alpha$-tocopherol, other forms of vitamin $\mathrm{E}$, such as $\gamma$-tocopherol, $\delta$-tocopherol, $\gamma$-tocotrienol, and $\delta$-tocotrienol are more potent in inhibiting multiple cancer-promoting pathways and have far superior cancer preventive efficacy (Jiang, 2017). The 
question of whether there are optimal ratios for these agents in regard to cancer prevention needs to be investigated. The measurement of baseline blood levels of the different forms of tocopherol is of importance, since cancer preventive effects may be confined to individuals with low blood levels (Yang et al., 2012).

In addition, the findings of recent gene-supplement interaction studies suggest that the effects of vitamin $\mathrm{E}$ on total risk of cancer (Hall et al. 2019a) and risk of colorectal cancer (Hall et al., 2019b) may be influenced by genetic variation in catechol-O-methyltransferase (COMT), an enzyme that metabolizes catecholamines. This variation may increase the risk in some people while decreasing it in others. Pharmacogenetic analysis of COMT gene and cancer prevention in two large randomized trials revealed a statistically significant decline in colorectal cancer by alpha-tocopherol when COMT was inhibited by siRNA (Hall et al., 2019a). Thus, further studies are required to examine the contributions of genetic variation to the efficacy and safety of vitamin E supplementation.

\section{Conclusions}

The supplementation of omega-3 PUFAs has been found to be associated with the promotion of health and a reduction in the risk of various diseases. However, a potential drawback of omega-3 supplements, particularly when administered at supra-physiological doses over prolonged periods of time, is the occurrence of unwanted adverse effects, such as various kinds of cancer. These may become apparent many years following supplementation and therefore elude detection.

Possible adverse effects of long-term administration of vitamin E added as an antioxidant to fish oil supplements need to be taken into consideration. While cancer preventive activity of vitamin $\mathrm{E}$ has been suggested by some epidemiological studies, large-scale human trials have shown increased rates of prostate cancer in men taking $\alpha$-tocopherol supplementation. Further investigations are needed to assess the role of genetic variation as a determinant of the benefits and possible harms of vitamin E supplemented for health promotion.

Potentially negative health effects resulting from the consumption of oxidized lipids are a cause for concern. Omega-3 PUFAs oxidize easily during storage, with the result that PUFA supplements contain lipid peroxides and secondary oxidation products, while the levels of unoxidized fatty acids gradually diminish. PUFA oxidation can be reduced, but not prevented, by added antioxidants; little is known about the degree of lipid oxidation in omega-3 supplements. The composition of a fish oil supplement in terms of PUFA levels cannot therefore be inferred from the concentrations shown on the label. The oils in omega-3 supplements may differ substantially from those in fresh fish, and the supplements constitute a mixture of DHA, EPA, other fatty acids, additives, and unspecified concentrations of potentially harmful lipid peroxides and secondary oxidation products. The levels of oxidation found in several studies suggest that omega-3 PUFA supplements contain oxidized products exceeding voluntary industry standard levels. The biological effects and health consequences of the intake of oxidized fish oils remain largely unknown. Given the harmful effects of oxidized lipid products demonstrated in animal experiments and the paucity of available data in humans, it is not, at present, possible to draw a definitive conclusion as to whether fish oils are safe following oxidation. There is therefore an urgent need to examine the effects of oxidized oils on human health and to establish safe limits of oxidation for human consumption. In addition, new antioxidants and compounds stabilizing omega- 3 fatty acids should be investigated.

In summary, short-term adverse effects of omega-3 PUFAs do not appear to give cause for concern. However, in view of potentially increased cancer risks associated with omega-3 supplementation, possibly due to PUFAs, oxidation products or added vitamin E, caution is advised in the recommendation of PUFA supplementation over extended periods of time. Deleterious effects of omega-3 PUFA supplements may be particularly relevant when administered during vulnerable phases of life, such as prenatal development, childhood, and adolescence. A balanced approach should carefully weigh potentially harmful effects of the supplementation of omega-3 PUFAs against their overall health benefits.

\section{References}

Albert, B.B., Cameron-Smith, D., Hofman, P.L., and Cutfield, W.S. (2013). Oxidation of marine omega-3 supplements and human health. BioMed Res. Int. 2013: 464921.

Albert, B.B., Derraik, J.G.B., Cameron-Smith, D., Hofman, P.L., Tumanov, S., Villas-Boas, S.G., Garg, M.L., and Cutfield, W.S. (2015). Fish oil supplements in New Zealand are highly oxidised and do not meet label content of n-3 PUFA. Sci. Rep. 5: 7928.

Arab-Tehrany, E., Jacquot, M., Gaiani, C., Imran, M., Desobry, A., and Linder, M. (2012). Beneficial effects and oxidative stability of omega-3 longchain polyunsaturated fatty acids. Trends Food Sci. 25: 24-33.

Bannenberg, G., Mallon, C., Edwards, H., Yeadon, D., Yan, K., Johnson, H. and Ismail, A. (2017). Omega-3 long-chain polyunsaturated fatty acid content and oxidation state of fish oil supplements in New Zealand. Sci. Rep. 7: 1488.

Barnes, P.M., Bloom, B., and Nahin, R.L. (2008). Complementary and alternative medicine use among adults and children: United States, 2007. Natl Health Stat Report 10(12): 1-23.

Bartsch, H., and Nair, J. (2006). Chronic inflammation and oxidative stress in the genesis and perpetuation of cancer: role of lipid peroxidation, DNA damage, and repair. Langenbeck's Arch. Surgery 391: 499-510.

Basu, A.K., and Marnett, L.J. (1983). Unequivocal demonstration that malondialdehyde is a mutagen. Carcinogenesis 4: 331-333.

Benzie, I.F.F. (1996). Lipid peroxidation: a review of causes, consequences, measurement and dietary influences. Int. J. Food Sci. Nutr. 47: 233-261.

Berquin, I.M., Min, Y., Wu, R., Wu, J., Perry, D., Cline, J.M., Thomas, M.J., Thornburg, T., Kulik, G., Smith, A., Edwards, I.J., D’Agostino Jr, R., Zhang, H., Wu, H., Kang, J.X., and Chen, Y.Q. (2007). Modulation of prostate cancer genetic risk by omega- 3 and omega- 6 fatty acids. J. Clin. Investig. 117: 1866-1875.

Bosch, J., Gerstein, H.C., Dagenais, G.R., Díaz, R., Dyal, L., Jung, H., Maggiono, A.P., Probstfield, J., Ramachandran, A., Riddle, M.C., Rydén, L.E., and Yusuf, S. (2012). n-3 fatty acids and cardiovascular outcomes in patients with dysglycaemia. N. Engl. J. Med. 367: 309-318.

Brasky, T.M., Till, C., White, E., Neuhouser, M.L., Song, X., Goodman, P. Thompson, I.M., King, I.B., Albanes, D., and Kristal, A.R. (2011). Serum phospholipid fatty acids and prostate cancer risk: results from the Prostate Cancer Prevention Trial. Am. J. Epidemiol. 173: 14291439.

Brasky, T.M., Darke, A.K., Song, X., Tangen, C.M., Goodman, P.J., Thompson, I.M., Meyskens Jr, F.L., Goodman, G.E., Minasian, L.M., Parnes, H.L., Klein, E.A., and Kristal, A.R. (2013). Plasma phospholipid fatty acids and prostate cancer risk in the SELECT trial. J. Natl. Cancer Inst. 105: 1132-1141.

Chan, J.M., Stampfer, M.J., Ma, J., Rimm, E.B., Willett, W.C., and Giovannucci, E.L. (1999). Supplemental vitamin E intake and prostate cancer risk in a large cohort of men in the United States. Cancer Epidemiol. Biomarkers Prev. 8: 893-899.

Chapkin, R.S., Kim, W., Lupton, J.R., and McMurray, D.N. (2009). Dietary docosahexaenoic and eicosapentaenoic acid: emerging mediators of inflammation. Prostaglandins Leukot. Essent. Fatty Acids 81: 187191.

Cho, S.H., and Choi, Y.S. (1994). Lipid peroxidation and antioxidant status 
is affected by different vitamin E levels when feeding fish oil. Lipids 29: 47-52.

Crowe, F.L., Appleby, P.N., Travis, R.C., Barnett, M., Brasky, T.M., Bueno-deMesquita, H.B., Chajes, V., Chavarro, J.E., Chirlaque, M.D., English, D.R., Gibson, R.A., Giles, G.G., Goodman, G.E., Henning, S.M., Kaaks, R., King, I.B., Kolonel, L.N., Kristal, A.R., Neuhouser, M.L., Park, S.Y, Severi, G., Siddiq, A., Stampfer, M.J., Stattin, P., Tangen, C.M., Tjønneland, A., Trichopoulos, D., Tumino, R., Wilkens, L.R., Key, T.J., Allen, N.E., and Endogenous Hormones, Nutritional Biomarkers and Prostate Cancer Collaborative Group (2014). Circulating fatty acids and prostate cancer risk: individual participant meta-analysis of prospective studies. J. Natl. Cancer Inst. 106(9): dju240.

Damico, K.E., Stoll, A.L., Marangell, L.B., and Cohen, B.M. (2002). How blind is double-blind? A study of fish oil versus placebo. Prostaglandins Leukot. Essent. Fatty Acids 66: 393-395.

EFSA Panel on Biological Hazards (BIOHAZ). (2010). Scientific opinion on fish oil for human consumption. Food hygiene, including rancidity. EFSA J. 8: 1874.

Emsley, R., Myburgh, C., Ousthuizen, P., and van Rensburg, S.J. (2002). Randomized, placebo-controlled study of ethyl-eicosapentaenoic acid as supplemental treatment in schizophrenia. Am. J. Psychiatry 159: 1596-1598.

Emsley, R., Niehaus, D.J., Koen, L., Oosthuizen, P.P., Turner, H.J., Carey, P., van Rensburg, S.J., Maritz, J.S., and Murck, H. (2006). The effects of eicosapentaenoic acid in tardive dyskinesia: a randomized, placebocontrolled trial. Schizophr. Res. 84: 112-120.

Eritsland, J., Arnesen, H., Seljeflot, I., and Kierulf, P. (1995). Long-term effects of $n-3$ polyunsaturated fatty acids on haemostatic variables and bleeding episodes in patients with coronary heart disease. Blood Coagul. Fibrinolysis. 6: 17-22.

Esterbauer, H. (1993). Cytotoxicity and genotoxicity of lipid-oxidation products. Am. J. Clin. Nutr. 57: 779S-785S.

Fantoni, C.M., Cuccio, A.P., and Barrera-Arellano, D. (1996). Brazilian encapsulated fish oils: oxidative stability and fatty acid composition. J. Am. Oil Chem. Soc. 73: 251-253.

Fierens, C., and Corthout, J. (2007). Omega-3 fatty acid preparations-a comparative study. J. Pharm. Belg. 62: 115-119.

Gaziano, J.M., Glynn, R.J., Christen, W.G., Kurth, T., Belanger, C., MacFadyen, J., Bubes, V., Manson, J.E., Sesso, H.D., and Buring, J.E. (2009). Vitamins $E$ and $C$ in the prevention of prostate and total cancer in men: the Physicians' Health Study II randomized controlled trial. JAMA 301: 52-62.

Gerber, M. (2012). Omega-3 fatty acids and cancers: a systematic update review of epidemiological studies. Br. J. Nutr. 107(Suppl. 2): S228S239.

Gonzalez, M.J., Gray, J.I., Schemmel, R.A., Dugan, L., and Welsch, C.W. (1992). Lipid peroxidation products are elevated in fish oil diets even in the presence of added antioxidants. J. Nutr. 122: 2190-2195.

Grimm, M.O.W., Haupenthal, V.J., Mett, J., Stahlmann, C.P., Blümel, T., Mylonas, N.T., Endres, K., Grimm, H.S., and Hartmann, T. (2016). Oxidized docosahexaenoic acid species and lipid peroxidation products increase amyloidogenic amyloid precursor protein processing. Neurodegener. Dis. 16: 44-54.

Guitard, R., Paul, J.F., Nardello-Rataj, V., and Aubry, J.M. (2016). Myricetin, rosmarinic and carnosic acids as superior natural antioxidant alternatives to $\alpha$-tocopherol for the preservation of omega-3 oils. Food Chem. 213: 284-295.

Gutowski, M., and Kowalczyk, S. (2013). A study of free radicals chemistry: their role and pathophysiological significance. Acta Biochim. Polon. 16: 1-16.

Haglund, O., Luostarinen, R., Wallin, R., Wibell, L., and Saldeen, T. The effects of fish oil on triglycerides, cholesterol, fibrinogen and malondialdehyde in humans supplemented with vitamin E. J. Nutr. 121: 165-169.

Hall, K.T., Buring, J.E., Mukamal, K.J., Moorthy, M.V., Wayne, P.M., Kaptchuk, T.J., Battinelli, E.M., Ridker, P.M., Sesso, H.D., Weinstein, S.J., Albanes, D., Cook, N.R., and Chasman, D.I. (2019a). COMT modifies alpha-tocopherol effects in cancer prevention: gene-supplement interactions in two randomized clinical trials. J. Natl. Cancer Inst. 111: djy204.

Hall, K., Weinstein, S., Buring, J., Mukamal, K., Moorthy, M.V., Ridker, P.,
Albanes, D., Cook, N., Chasman, D., and Sesso, H. (2019b). COMT effects on vitamin $\mathrm{E}$ and colorectal cancer, in-vitro and in two randomized trials (P15-005-19). Curr. Dev. Nutr. 3(Suppl 1): nzz037.P15005-19.

Halvorsen, B.L., and Blomhoff, R. (2011). Determination of lipid oxidation products in vegetable oils and marine omega-3 supplements. Food Nutr. Res. 55: 5792.

Hasiewicz-Derkacz, K., Kulma, A., Czuj, T., Prescha, A., Zuk, M., Grajzer, M., Łukaszewicz, M., and Szopa, J. (2015). Natural phenolics greatly increase flax (Linum usitatissimum) oil stability. BMC Biotechnol. 15: 62.

Helzlsouer, K.J., Huang, H.Y., Alberg, A.J., Hoffman, S., Burke, A., Norkus, E.P., Morris, J.S., and Comstock, G.W. (2000). Association between alpha-tocopherol, gamma-tocopherol, selenium, and subsequent prostate cancer. J. Natl. Cancer Inst. 92: 2018-2023.

Hogan, S.A., O'Riordan, E.D., and O'Sullivan, M. (2003). Microencapsulation and oxidative stability of spray-dried fish oil emulsions. J. Microencapsul. 20: 675-688.

Huang, H.Y., Alberg, A.J., Norkus, E.P., Hoffman, S.C., Comstock, G.W., and Helzlsouer, K.J. (2003). Prospective study of antioxidant micronutrients in the blood and the risk of developing prostate cancer. Am. J. Epidemiol. 157: 335-344.

Ioannidis, J.P. (2009). Adverse events in randomized trials: neglected, restricted, distorted, and silenced. Arch. Intern. Med. 169: 1737-1739.

Jackowski, S.A., Alvi, A.Z., Mirajkar, A., Imani, Z., Gamalevych, Y., Shaikh, N.A., and Jackowski, G. (2015). Oxidation levels of North American over-the-counter $n-3$ (omega-3) supplements and the influence of supplement formulation and delivery form on evaluating oxidative safety. J. Nutr. Sci. 4: e30.

Jiang, Q. (2017). Natural forms of vitamin E as effective agents for cancer prevention and therapy. Adv. Nutr. 8: 850-867.

Ju, J., Picinich, S.C., Yang, Z., Zhao, Y., Suh, N., Kong, A.N., and Yang, C.S. (2010). Cancer preventive activities of tocopherols and tocotrienols. Carcinogenesis 31: 533-542.

Kaneda, T., and Ishii, S. (1953). Studies on the nutritive value of lipids. VIII. Nutritive value or toxicity of highly unsaturated fatty acids. Bull. Jap. Soc. Sci. Fisheries 19: 171-177.

Kirsh, V.A., Hayes, R.B., Mayne, S.T., Chatterjee, N., Subar, A.F., Dixon, L.B., Albanes, D., Andriole, G.L., Urban, D.A., and Peters, U. (2006). Supplemental and dietary vitamin $\mathrm{E}$, beta-carotene, and vitamin $\mathrm{C}$ intakes and prostate cancer risk. J. Natl. Cancer Inst. 98: 245-254.

Klein, E.A., Thompson Jr, I.M., Tangen, C.M., Crowley, J.J., Lucia, M.S. Goodman, P.J., Minasian, L., Ford, L.G., Parnes, H.L., Gaziano, J.M., Karp, D.D., Lieber, M.M., Walther, P.J., Klotz, L., Parsons, J.K., Chin, J.L., Darke, A.K., Lippman, S.M., Goodman, G.E., Meyskens Jr, F.L., and Baker, L.H. (2011). Vitamin E and the risk of prostate cancer: the Selenium and Vitamin E Cancer Prevention Trial (SELECT). JAMA 306: 1549-1556.

Kolanowski, W. (2010). Omega-3 LC PUFA contents and oxidative stability of encapsulated fish oil dietary supplements. Int. J. Food Prop. 13: 498-511.

Kolanowski, W., Laufenberg, G., and Kunz, B. (2004). Fish oil stabilisation by microencapsulation with modified cellulose. Int. J. Food Sci. Nutr. 55: $333-343$.

Lange, K.W. (2019a). Lipids in the treatment of neurodegenerative diaseases. In: Shahidi, F. (Ed.). Bailey's industrial oil and fat products (7th Ed.). Wiley, .

Lange, K.W. (2019b). Lipids in the treatment of mental disorders. In: Shahidi, F. (Ed.). Bailey's industrial oil and fat products (7th Ed.). Wiley.

Lange, K.W. (2019c). Omega-3 fatty acids and mental health. Global Health J. 3.

Larsson, S.C., Kumlin, M., Ingelman-Sundberg, M., and Wolk, A. (2004). Dietary long-chain $n-3$ fatty acids for the prevention of cancer: a review of potential mechanisms. Am. J. Clin. Nutr. 79: 935-945.

Lee, I.M., Cook, N.R., Gaziano, J.M., Gordon, D., Ridker, P.M., Manson, J.E., Hennekens, C.H., and Buring, J.E. (2005). Vitamin E in the primary prevention of cardiovascular disease and cancer: the Women's Health Study: a randomized controlled trial. JAMA 294: 56-65.

Lippman, S.M., Klein, E.A., Goodman, P.J., Lucia, M.S., Thompson, I.M., Ford, L.G., Parnes, H.L., Minasian, L.M., Gaziano, J.M., Hartline, J.A., Parsons, J.K., Bearden, J.D. 3rd., Crawford, E.D., Goodman, G.E., Clau- 
dio, J., Winquist, E., Cook, E.D., Karp, D.D., Walther, P., Lieber, M.M., Kristal, A.R., Darke, A.K., Arnold, K.B., Ganz, P.A., Santella, R.M., Albanes, D., Taylor, P.R., Probstfield, J.L., Jagpal, T.J., Crowley, J.J., Meyskens, F.L. Jr., Baker, L.H., and Coltman, C.A. Jr. (2009). Effect of selenium and vitamin $\mathrm{E}$ on risk of prostate cancer and other cancers: the Selenium and Vitamin E Cancer Prevention Trial (SELECT). JAMA 301: 39-51.

MacLean, C.H., Newberry, S.J., Mojica, W.A., Khanna, P., Issa, A.M., Suttorp, M.J., Lim, Y.W., Traina, S.B., Hilton, L., Garland, R., and Morton, S.C. (2006). Effects of omega-3 fatty acids on cancer risk: a systematic review. JAMA 295: 403-415.

Mahabir, S., Schendel, K., Dong, Y.Q., Barrers, S.L., Spitz, M.R., and Forman, M.R. Dietary $\alpha-, \beta-, \gamma$ - and $\delta$-tocopherols in lung cancer risk. Int. J. Cancer 123: 1173-1180.

Marnett, L.J. (1999). Lipid peroxidation-DNA damage by malondialdehyde. Mutat. Res. 424: 83-95.

Maruyama, W., Shaomoto-Nagai, M., Kato, Y., Hisaka, S., Osawa, T., and Naoi, M. (2014). Role of lipid peroxide in the neurodegenerative disorders. Subcell. Biochem. 77: 127-136.

Matsuo, N. (1954). Studies on the toxicity of fish oil. J. Biochem. 41: 481487.

Mehta, D. (Ed.). (2004). British National Formulary. British Medical Association and Royal Pharmaceutical Society of Great Britain, London.

Mozaffarian, D., and Rimm, E.B. (2006). Fish intake, contaminants, and human health: evaluating the risks and the benefits. JAMA 296: 1885-1899.

Opperman, M., and Benade, S. (2013). Analysis of the omega-3 fatty acid content of South African fish oil supplements: a follow-up study. Cardiovasc. J. Afr. 24: 297-302.

Ottestad, I., Vogt, G., Retterstøl, K., Myhrstad, M.C., Haugen, J.E., Nilsson, A., Ravn-Haren, G., Nordvi, B., Brønner, K.W., Andersen, L.F., Holven, K.B., and Ulven, S.M. (2012). Oxidised fish oil does not influence established markers of oxidative stress in healthy human subjects: a randomised controlled trial. Br. J. Nutr. 108: 315-326.

Pak, C.S. (2005). Stability and quality of fish oil during typical domestic application. United Nations University, Reykjavik, Iceland.

Pamplona, R., Dalfó, E., Ayala, V., Bellmunt, M.J., Prat, J., Ferrer, I., and Portero-Otín, M. (2005). Proteins in human brain cortex are modified by oxidation, glycoxidation, and lipoxidation. Effects of Alzheimer disease and identification of lipoxidation targets. J. Biol. Chem. 280: 21522-21530

Piche, L.A., Draper, H.H., and Cole, P.D. (1988). Malondialdehyde excretion by subjects consuming cod liver oil vs a concentrate of $n-3$ fatty acids. Lipids 23: $370-371$.

Rizos, E.C., Ntzani, E.E., Bika, E., Kostapanos, M.S., and Elisaf, M.S. (2012). Association between omega-3 fatty acid supplementation and risk of major cardiovascular disease events: a systematic review and metaanalysis. JAMA 308: 1024-1033.

Sahashi, Y. (1933). Nutritive value of sperm whale oil and finback whale oil. Sci. Papers Inst. Phys. Chem. Res. Tokyo 20: 245-253.

Sayre, L.M., Zelasko, D.A., Harris, P.L.R., Perry, G., Salomon, R.G., and Smith, M.A. (1997). 4-hydroxynonenal-derived advanced lipid per- oxidation end products are increased in Alzheimer's disease. J. Neurochem. 68: 2092-2097.

Sfanos, K.S., and De Marzo, A.M. (2012). Prostate cancer and inflammation: the evidence. Histopathology 60: 199-215.

Shahidi, F. (2015). Omega-3 fatty acids and marine oils in cardiovascular and general health: a critical overview of controversies and realities. J. Funct. Foods 19: 797-800.

Shahidi, F., and Ambigaipalan, P. (2018). Omega-3 polyunsaturated fatty acids and their health benefits. Annu. Rev. Food Sci. Technol. 9: 345-381.

Shahidi, F., and Zhong, Y. (2010). Lipid oxidation and improving the oxidative stability. Chem. Soc. Rev. 39: 4067-4079.

Somekawa, E. (1933). On the production of seborrhea in rat by feeding with whale oil. Sci. Papers Inst. Phys. Chem. Res. Tokyo 30: 149-157.

Spiteller, G. (2005). The relation of lipid peroxidation processes with atherosclerosis: A new theory on atherogenesis. Mol. Nutr. Food Res. 49: 999-1013.

Sydenham, E., Dangour, A.D., and Lim, W.S. (2012). Omega 3 fatty acid for the prevention of cognitive decline and dementia. Cochrane Database Syst. Rev. 6: CD005379.

Veierød, M.B., Thelle, D.S., and Laake, P. (1997). Diet and risk of cutaneous malignant melanoma: a prospective study of 50,757 Norwegian men and women. Int. J. Cancer 71: 600-604.

Wang, W., Bergh, A., and Damber, J.E. (2009). Morphological transition of proliferative inflammatory atrophy to high-grade intraepithelial neoplasia and cancer in human prostate. Prostate 69: 1378-1386.

Wang, M., Dhingra, K., Hittelman, W.N., Liehr, J.G., de Andrade, M., and Li, D. (1996). Lipid peroxidation-induced putative malondialdehydeDNA adducts in human breast tissues. Cancer Epidemiol. Biomarkers Prev. 5: 705-710.

Wang, C., Harris, W.S., Chung, M., Lichtenstein, A.H., Balk, E.M., Kupelnick, B., Jordan, H.S., and Lau, J. (2006). n-3 fatty acids from fish or fish-oil supplements, but not $\alpha$-linolenic acid, benefit cardiovascular disease outcomes in primary- and secondary prevention studies: a systematic review. Am. J. Clin. Nutr. 84: 5-17.

Yakubenko, V.P., and Byzova, T.V. (2017). Biological and pathophysiological roles of end-products of DHA oxidation. Biochim. Biophys. Acta 1862: 407-415.

Yang, C.S., Suh, N., and Kong, A.N.T. (2012). Does vitamin E prevent or promote cancer? Cancer Prev. Res. 5: 701-705.

Yokoyama, M., Origasa, H., Matsuzaki, M., Matsuzawa, Y., Saito, Y., Ishikawa, Y., Oikawa, S., Sasaki, J., Hishida, H., Itakura, H., Kita, T., Kitabatake, A., Nakaya, N., Sakata, T., Shimada, K., and Shirato, K. (2007). Effects of eicosapentaenoic acid on major coronary events in hypercholesterolaemic patients (JELIS): a randomised open-label, blinded endpoint analysis. Lancet 369: 1090-1098.

Zhong, Y., and Shahidi, F. (2011). Lipophilized epigallocatechin gallate (EGCG) derivatives as novel antioxidants. J. Agric. Food Chem. 59: 6526-6533.

Zuta, P., Simpson, B., Zhao, X., and Leclerc, L. (2007). The effect of $\alpha$-tocopherol on the oxidation of mackerel oil. Food Chem. 100: 800-807. 